ARTICLE

\title{
A polymer scaffold for self-healing perovskite solar cells
}

Yicheng Zhao ${ }^{1,2, \star}$, Jing Wei ${ }^{1,2, \star}$, Heng $\mathrm{Li}^{1,2, \star}$, Yin Yan ${ }^{1,2}$, Wenke Zhou ${ }^{1,2}$, Dapeng $\mathrm{Yu}^{1,2} \&$ Qing Zhao ${ }^{1,2}$

Advancing of the lead halide perovskite solar cells towards photovoltaic market demands large-scale devices of high-power conversion efficiency, high reproducibility and stability via low-cost fabrication technology, and in particular resistance to humid environment for long-time operation. Here we achieve uniform perovskite film based on a novel polymer-scaffold architecture via a mild-temperature process. These solar cells exhibit efficiency of up to $\sim 16 \%$ with small variation. The unencapsulated devices retain high output for up to $300 \mathrm{~h}$ in highly humid environment (70\% relative humidity). Moreover, they show strong humidity resistant and self-healing behaviour, recovering rapidly after removing from water vapour. Not only the film can self-heal in this case, but the corresponding devices can present power conversion efficiency recovery after the water vapour is removed. Our work demonstrates the value of cheap, long chain and hygroscopic polymer scaffold in perovskite solar cells towards commercialization.

\footnotetext{
${ }^{1}$ State Key Laboratory for Mesoscopic Physics, School of Physics, Peking University, Beijing, 100871, China. ${ }^{2}$ Collaborative Innovation Center of Quantum Matter, Beijing, 100084, China. * These authors contribute equally to this work. Correspondence and requests for materials should be addressed to Q.Z. (email: zhaoqing@pku.edu.cn).
} 
T he rapid rising of the lead halide perovskite solar cells (PSCs), typically based on $\mathrm{CH}_{3} \mathrm{NH}_{3} \mathrm{PbI}_{3}\left(\mathrm{MAPbI}_{3}\right)$ or its analogues, demonstrate great potential for market applications ${ }^{1-13}$. The worldwide power conversion efficiency (PCE) race for the perovskite solar cells has stimulated the highest record of $>20 \%$ update via solvent engineering ${ }^{8}$, interface engineering ${ }^{5}$ and composition engineering ${ }^{10}$, which approaches the best of polycrystalline silicon modules. The excellent performance of PSCs is attributed to the high absorption coefficient, weak exciton binding energy, and long diffusion length of the perovskite phase ${ }^{12,14-17}$. Two dominant device architectures, namely mesoporous scaffold ${ }^{1-3}$ and planar heterojunction structures ${ }^{4,5}$ have been developed. The PCE in mesoporous scaffold architecture depends on the pore size, porosity and morphology of the metal oxide nanoparticles, which dominantly determine the coverage, morphology variation of the perovskite layer and the carrier lifetime. Moreover, the fabrication of inorganic metal oxide mesoporous scaffold is complicated and needs sintering at high temperature of $>450{ }^{\circ} \mathrm{C}$ (refs 2,3), which makes the fabrication more expensive. The planar heterojunction PSCs fabricated layer by layer is either fabricated via high vacuum deposition ${ }^{4}$ or solution-based method $^{5,18}$. However, the low-cost solution process is rather challenging to form homogeneous film due to the dewetting process and sensitivity to the atmosphere ${ }^{18-20}$. Recently, progress has been reported to control the nucleation rate by changing dissolvent or temperature of the substrate ${ }^{21,22}$. Besides high efficiency and high reproducibility, long-term stability is also a crucial barrier to commercialize the PSCs, because the lead halide perovskite materials are very sensitive to ambient humidity and easy to dissolve and degrade in humid environment ${ }^{5,23,24}$. Therefore, it is very challenging and pressing to develop ultra stable and high PCE devices resistant to hostile operation environment.

Here we report a novel perovskite solar cell architecture based on an insulating polymer scaffold structure. The polymer-scaffold perovskite layer is simply fabricated via a single one-step process under mild temperature of $105^{\circ} \mathrm{C}$. The as-made polymer-scaffold perovskite solar cell (PPSC) devices demonstrate high PCE up to $\sim 16 \%$ under standard AM1.5 illumination and very small efficiency variation compared with that without the insulating polymer. Remarkably, unsealed PPSCs exhibit excellent performance in stability test in highly humid environment ( $70 \%$ relative humidity), which can endure the moisture for over $300 \mathrm{~h}$. Most strikingly, the PPSCs show strong self-healing or water resistant effect under vapour spray. The perovskite film, as well as the corresponding devices can recover rapidly to its original phase and performance after being vapour sprayed and dried in ambient air, respectively.

\section{Results}

Design, fabrication and characterization of PPSCs. The PPSC architecture inherits the basic structure of PSCs with inorganic mesoporous scaffold ${ }^{1-3}$, instead, the inorganic nanocrystal scaffolds are replaced with long- and flexible-polymer chain networks, which can be processed under mild temperature (Fig. 1a-c). The fabrication of PPSC is similar to that of planar heterojunction PSCs, except for the precursor solution preparation (Fig. 1d). Long-chain insulating polymers, dissolved in precursor solution, assemble the polymer scaffold simultaneously as the precursor solution is spin coated on the substrate. The selected polymer should be chemically inert to ingredients for perovskite synthesis; it should also act as an electrical insulator to guarantee the effective transport of photo-generated carriers. Here polyethylene glycol (PEG), which meets the requirements, is chosen to be added in the precursor solution of $\mathrm{PbCl}_{2}$ and $\mathrm{CH}_{3} \mathrm{NH}_{3} \mathrm{I}$ (MAI; $1: 3$ molar ratio) in dimethylformamide. The molar ratio of PEG monomers $\left(\mathrm{C}_{2} \mathrm{H}_{4} \mathrm{O}\right)$ to ultimate product $\mathrm{MAPbI}_{3}$ is close to 1:1 (PEG in $40 \mathrm{mg} \mathrm{ml}^{-1}$ ). The PEG scaffold perovskite absorber layer was prepared on the $\mathrm{TiO}_{2}(\sim 40 \mathrm{~nm}$ thickness)-coated fluorine doped tin oxide (FTO) glass by spin coating followed by annealing at $105^{\circ} \mathrm{C}$ for 70 min. 2,29,7,79-tetrakis-(N,N-di-p-methoxyphenylamine) 9,99-spirobifluorene (Spiro-OMeTAD) and gold were used as the hole transport layer and electrode, respectively.

Figure 1e,f present top-view scanning electron microscope (SEM) images of the perovskite films without and with polymer scaffold. Those without scaffold exhibited large pinholes and bare conducting substrates, increasing the risk of short circuits. Those with scaffold demonstrated continuous and complete coverage. The cross-section SEM image showed the perovskite layer without polymer to have considerable variation in thickness and many voids (Fig. 1g). The film with polymer was uniform in thickness over large area (Fig. 1h). The PEG scaffold can also work in another precursor solution $\mathrm{PbI}_{2}$ :MAI (1:1) (Supplementary Fig. 1). PEG plays an important role in improvement of the film quality for the following reasons. First, the simultaneously formed PEG scaffold, which is formed by entangled long-chain molecules, acts as a three-dimensional skeleton to support perovskite crystals, causing it to cover the substrate more uniformly (Fig. 1c), demonstrating an advantage over planar heterojunction PSCs. Uniformly distributed PEG scaffolds function as $\mathrm{Al}_{2} \mathrm{O}_{3}$ scaffolds ${ }^{3}$, and they can be produced in a much simpler and less costly manner. Second, the wetting properties of the precursor solution have been improved after introducing PEG (Supplementary Fig. 2), which can improve film morphology ${ }^{19}$. Third, PEG molecules in precursor solution can slow down the crystallization of perovskite from the X-ray diffraction characterization by tracking the intermediate phase in the crystallization process, which is shown below.

To confirm that PEG acts as scaffold in the architecture, detailed energy dispersive spectroscopy (EDS) analysis in a Cs-corrected scanning transmission electron microscope (STEM) was conducted for element mapping investigation (Fig. 2a-c). The high-angle annular dark field (HAADF) STEM image (Fig. 2a) reveals that the perovskite crystalline grains are surrounded by polymer material. The profiles of perovskite grains are highlighted with dashed lines according to the EDS mapping of $\mathrm{Pb}$ component (Fig. 2b). The amorphous material surrounding the perovskite grains is PEG in accordance with the EDS mapping of $\mathrm{O}$ element because only PEG contains $\mathrm{O}$. The $\mathrm{O}$ mapping demonstrates that PEG not only covers the perovskite grains, but also cross-links the neighbouring perovskite grains via self-assembly forming a polymer-scaffold network to support the perovskite grains (Fig. 2c). Above conclusion is also evidenced by the fact that $\mathrm{O}$ mapping covers larger area than $\mathrm{Pb}$ and extends from crystal boundaries, indicating that the perovskite grains are imbedded in the PEG networks, corresponding well to the HAADF-STEM image. In addition, the O element mapping on the cross-sectional area of the PPSC film confirms a homogeneous distribution of PEG molecules in the perovskite film (Supplementary Fig. 3). High-resolution transmission electron microscope image of perovskite grain demonstrates good crystal lattice (Supplementary Fig. 4), suggesting that PEG molecules do not damage the perovskite crystal structure.

The phase evolution of PEG scaffold perovskite film during annealing was characterized by $\mathrm{X}$-ray diffraction analysis (Fig. 2d). Over the course of $30-50 \mathrm{~min}$, the film turned from orange to yellow, the (110) and (220) peaks of perovskite phase ${ }^{25,26}$ became more pronounced and some new peaks appeared between 10 and $20^{\circ}$. The intermediate phase 
a

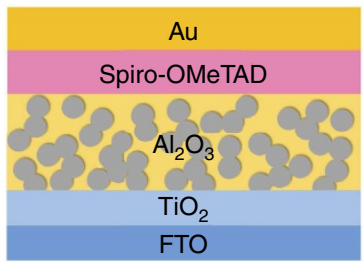

b

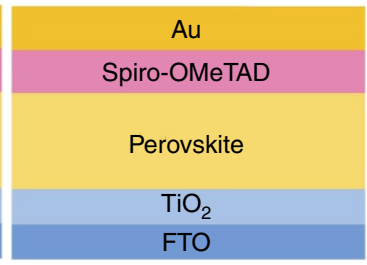

c

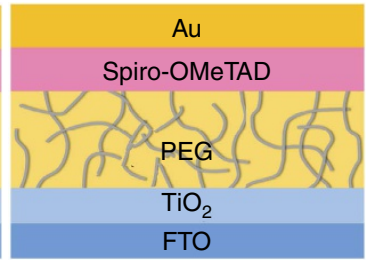

d

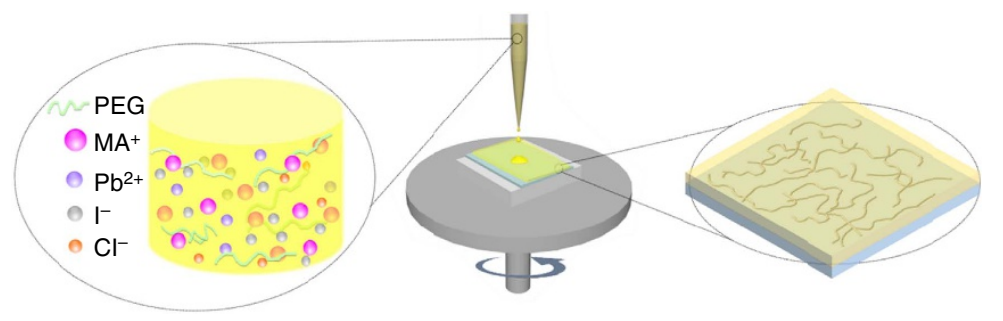

e
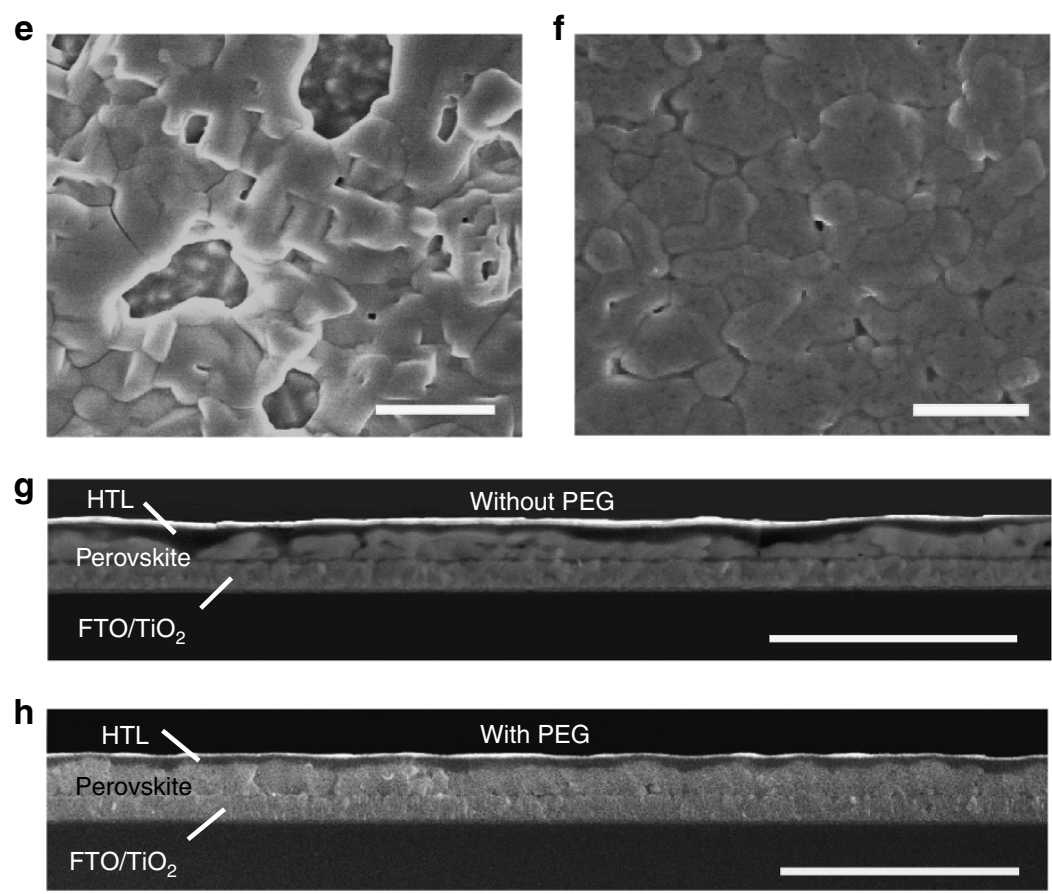

Figure 1 | Scheme and morphology of polymer-scaffold perovskite solar cells. Schematic diagram of mesoporous-scaffold-structured PSC (a), planarheterojunction-structured PSC (b) and polymer-scaffold structured PSC (c). (d) Schematic diagram showing the fabrication process of perovskite film with polymer scaffold using one-step spin coating method. (e,f) Top-view SEM images of the perovskite films (e) without PEG and (f) with PEG. Scale bar, $1 \mu$ m. $(\mathbf{g}, \mathbf{h})$ Cross-sectional SEM images of the perovskite solar cells (g) without PEG and (h) with PEG scaffold. Scale bar, $3 \mu \mathrm{m}$.

disappeared after annealing for $60 \mathrm{~min}$, and the sample became deep black at $105^{\circ} \mathrm{C}$ after $70 \mathrm{~min}$ of annealing, with stronger (110) and (220) peaks. X-ray diffraction patterns of perovskite film without PEG and with PEG under the same $100^{\circ} \mathrm{C}$ sintering temperature are also shown in Supplementary Fig. 5. Note that intermediate phase disappears after $70 \mathrm{~min}$ in film without PEG. While in film with PEG, intermediate phase disappears after $90 \mathrm{~min}$ (Supplementary Note 1), which strongly suggests a slower crystallization process in PEG scaffold perovskite film.

Photoluminescence (PL) spectra were measured to verify whether excess recombination sites and defect states are induced in the PEG scaffold perovskite film ${ }^{27,28}$. Compared with the PL spectrum of pristine perovskite film, the intensity is not influenced after being coated with PEG (Fig. 3b), indicating the insulating nature of PEG, as shown in Fig. 3a. Figure $3 c$ shows the time-resolved PL spectra with and without PEG polymer scaffold, with the similar carrier lifetime by using single exponential fitting (110.8 ns with PEG, 120.1 ns without PEG). This result indicates $\sim 1 \mu \mathrm{m}$ diffusion length if diffusion coefficient is supposed to be $0.1 \mathrm{~cm}^{2} \mathrm{~s}^{-1}$, which is sufficient to guarantee effective collection efficiency. On the other hand, no visible shift (peak position of $760 \mathrm{~nm}$ ) and broadening (half width of $40 \mathrm{~nm}$ ) of peaks associated with perovskite layers with and without PEG scaffold is observed, indicating that PEG does not induce any excessive recombination (Supplementary Fig. 6).

Photovoltaic performance of PPSCs. The photovoltaic properties of PPSCs are characterized systematically. The PEG molecular weight and its concentration in precursor solution were found to play an important role in the performance of PPSCs. Figure $4 \mathrm{a}$ shows the current density-voltage $(J-V)$ curves of samples with PEG in different molecule weights $(12,000 / 20,000 /$ 

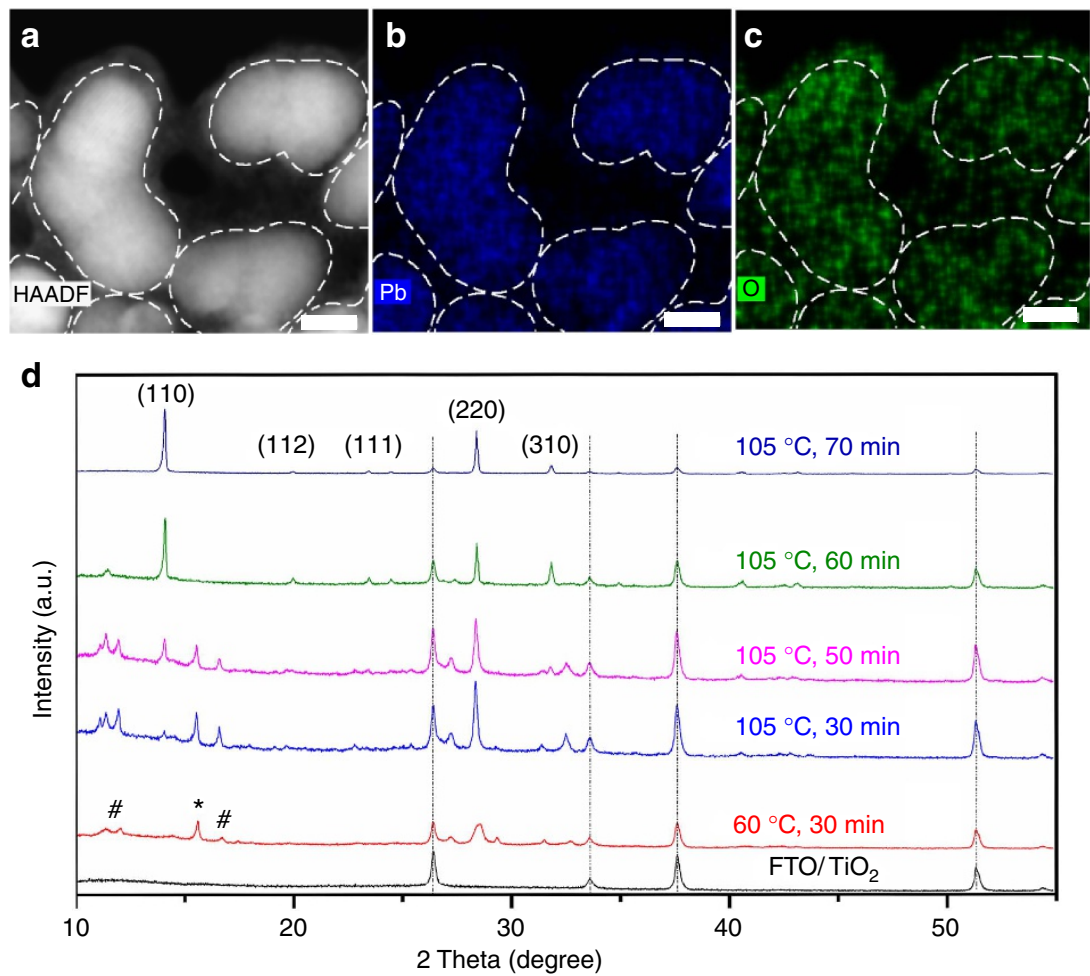

Figure 2 | Characterization and structure evolution of polymer-scaffold solar cells. (a) HAADF image of the perovskite film with PEG Scaffold in STEM mode. Scale bar, $10 \mathrm{~nm}$. (b) EDS mapping of Pb element of the peroskite film. Scale bar, $10 \mathrm{~nm}$. (c) EDS mapping of O element of the peroskite film. O signal corresponds to PEG distribution because only the PEG contains O element among the materials used in perovskite thin film synthesis. Scale bar, 10 nm. (d) X-ray diffraction patterns of the perovskite film (PEG molecule weight: 20,000 Da; PEG concentration: $40 \mathrm{mg} \mathrm{ml}^{-1}$ ) evolution with annealing time. '\#' symbols and '*' symbols denote the intermediate phase and $\mathrm{MAPbCl}_{3}$ phase, respectively.
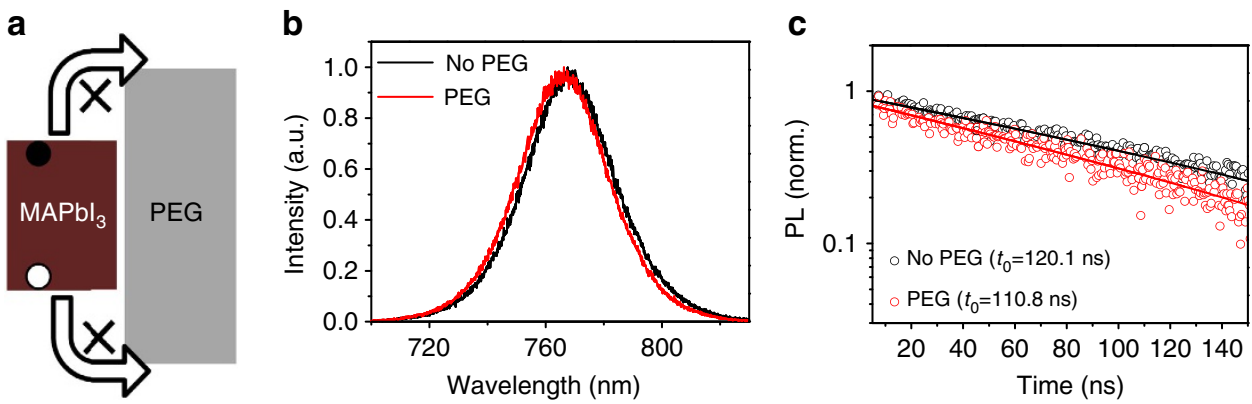

Figure 3 | Photoluminescence and energy-level alignment of polymer-scaffold perovskite films. (a) Schematic diagram of the energy offsets between $\mathrm{CH}_{3} \mathrm{NH}_{3} \mathrm{Pbl}_{3}$ and PEG. (b) PL spectra of pristine perovskite film (control) and the corresponding perovskite film after being coated with PEG. (c) Characteristics of PL transient spectra of PEG scaffold perovskite films and perovskite film without PEG, indicating the similar lifetime of carriers in perovskite with and without PEG scaffold.

$100,000 \mathrm{Da})$ measured under simulated AM1.5 illumination of $100 \mathrm{~mW} \mathrm{~cm}^{-2}$. The molecular weight of PEG, proportional to the length of polymer, has a significant effect on the performance of PPSCs, and the optimal molecular weight was found to be $>20,000$ Da because longer PEG molecules facilitate the formation of three-dimensional molecular network in the perovskite film, and guarantee uniform morphology. PEG concentration is also critical to devices because it is related to the series resistance. As demonstrated in Fig. 4b, the device shows much better performance with 20 and $40 \mathrm{mg} \mathrm{ml}^{-1}$ PEG concentration, and its PCE decreases at higher concentrations $\left(80 \mathrm{mg} \mathrm{ml}^{-1}\right)$ because the excess PEG in the film increases the series resistance and lowers the efficiency. Note that viscosity of the solution can be strongly influenced by PEG concentration and molecule weight, so the r.p.m. value of spin coating is optimized at different PEG concentration and molecule weight (see Methods for details) to guarantee $\sim 400 \mathrm{~nm}$ film thickness. The improved efficiency was also consistent with the increased recombination time constant ${ }^{28}$ in PPSCs, compared with that of control devices, as is shown in Fig. 4c. Owing to the improved coverage, the recombination time is almost one order of magnitude larger than that without polymer scaffold at zero bias. The highest PCE of $16 \%$ was obtained for PPSCs with optimal PEG molecule weight of $20,000 \mathrm{Da}$ and concentration of $20 \mathrm{mg} \mathrm{ml}^{-1}$, and showed an open voltage $\left(V_{\text {oc }}\right)$ of $0.98 \mathrm{~V}$, short-circuit current $\left(J_{\mathrm{sc}}\right)$ of $22.5 \mathrm{~mA} \mathrm{~cm}^{-2}$, and fill factor of 0.72 (Supplementary Fig. 7a). 

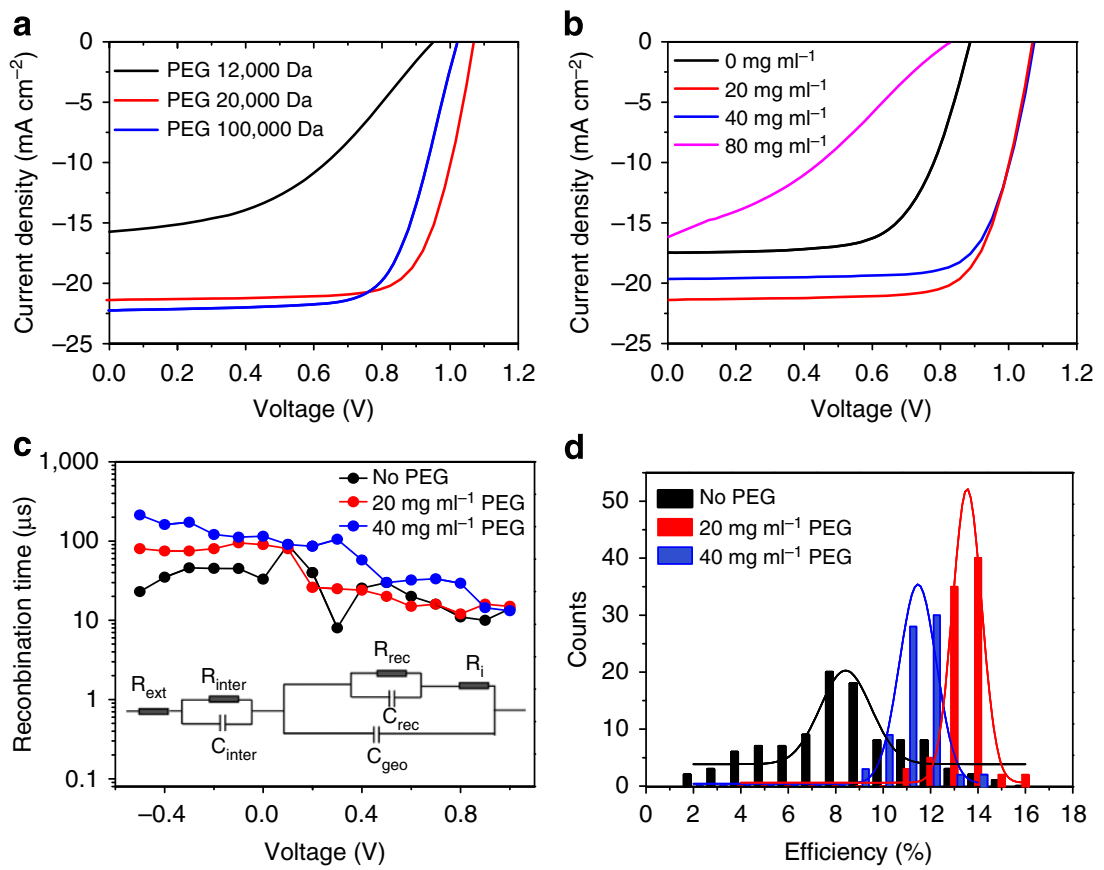

Figure 4 | Photovoltaic characterization of polymer-scaffold perovskite solar cells. (a) $J-V$ curves of the reverse scan based on precursor solution with different PEG molecular weight (concentration: $20 \mathrm{mg} \mathrm{ml}^{-1}$ ) measured from 1.5 to $-0.2 \mathrm{~V}$ under $500 \mathrm{mVs}^{-1}$. (b) J-V curves of the reverse scan based on precursor solution with different PEG concentration (molecular weight: 20,000 Da) measured from 1.5 to $-0.2 \mathrm{~V}$ under $500 \mathrm{mVs}^{-1}$. (c) Recombination time constant $R_{\text {rec }} . C_{\text {rec }}\left(R_{\text {rec, }}\right.$ recombination resistance, $C_{\text {rec, }}$ capacitance) under different applied voltage can be extracted by fitting the Nyquist plot using the inset circuit. (d) PCE distribution of perovskite solar cells with (20 or $40 \mathrm{mg} \mathrm{ml}^{-1}$ ) and without PEG scaffold. PCE values are extracted from reverse scan curve measured from 1.5 to $-0.2 \mathrm{~V}$ under $500 \mathrm{mVs}^{-1}$. The active area for testing is $9 \mathrm{~mm}^{2}$.

Another representative device shows a steady-state PCE of $15.4 \%$ at first $10 \mathrm{~s}$, and the PCE gradually drops down and eventually stabilized at $13.5 \%$ in $1,000 \mathrm{~s}(0.7 \mathrm{~V}$ bias, Supplementary Fig. 7b). Parallel devices present $H$ value from 10 to $30 \%$ under $500 \mathrm{mV} \mathrm{s}^{-1}$ if hysteresis index is defined $H=\left(\mathrm{PCE}_{\text {reverse }}-\mathrm{PCE}_{\text {forward }}\right) / \mathrm{PCE}_{\text {reverse }} \times 100 \%$ to characterize the hysteresis effect. $\mathrm{PCE}_{\text {reverse }}$ and $\mathrm{PCE}_{\text {forward }}$ represent $\mathrm{PCE}$ obtained from $J$ to $V$ measurement in reverse scan and forward scan, respectively. The statistical PCE distributions of $>100$ samples without and with (for two concentrations) polymer scaffolds are shown in Fig. 4d. The PPSCs exhibited a narrow PCE distribution for 20 and $40 \mathrm{mg} \mathrm{ml}^{-1}$, with an average efficiency of 14 and $12.5 \%$, respectively, but the PCE distribution of the PSCs without polymer scaffold was much broader, varying from 2 to $14 \%$, averaging at $\sim 8 \%$. The significant increase in PCE and high reproducibility of the PPSC devices are direct reflections of the uniform thickness and homogeneous morphology of the polymer-scaffold perovskite layer.

Improved stability in highly humid environment. More importantly, the insulating PEG scaffold structure can stabilize the PSCs in humid environment due to the strong hygroscopicity property of PEG. Here three groups of unsealed devices were prepared without and with PEG (two concentrations), respectively. Figure 5a shows the PCE evolution as a function of time of the three groups of devices in the dark under highly humid environment (relative humidity 70\%) without any sealing. In contrast to the fast PCE decay from 12 to $0.5 \%$ within $50 \mathrm{~h}$ of the pristine PSCs, the PPSCs retained $65 \%$ of its PCE after $300 \mathrm{~h}$ aging. Similarly, the $J_{\mathrm{sc}}, V_{\mathrm{oc}}$, and fill factor of the pristine sample decreased quickly during the first $50 \mathrm{~h}$, while those of the PPSCs retained relatively high values for up to $300 \mathrm{~h}$ (Supplementary Fig. 8a,b). Note that the device with PEG concentration of
$40 \mathrm{mg} \mathrm{ml}^{-1}$ showed better performance than the one with $20 \mathrm{mg} \mathrm{ml}^{-1}$ because more PEG can form a more compact layer, enhancing the moisture resistance of devices. We also studied the stability under continuous light illumination in $70 \%$ humidity for unsealed devices (Supplementary Fig. 8c,d). Photovoltaic performance degraded quickly within $10 \mathrm{~h}$ in the device without PEG scaffold, while PPSC retained $83 \%$ of its PCE during the same aging period. Similarly, $V_{\mathrm{oc}}, J_{\mathrm{sc}}$, and fill factor suffered substantial decrease in the first $10 \mathrm{~h}$ for pristine sample while they remained relatively high values in the presence of PEG. X-ray diffraction patterns of the perovskite film with PEG scaffold showed no structure destruction after $72 \mathrm{~h}$ continuous light irradiation, while the samples without PEG degraded into $\mathrm{PbI}_{2}$ quickly within $10 \mathrm{~h}$ (Supplementary Fig. 9). Evidence above strongly suggests that PEG can greatly protect perovskite film from decomposition under moisture attack and significantly improve the stability of PPSCs at very humid environment.

Self-healing property of PPSCs after vapour spray. In addition to its improved stability, the PPSC devices can demonstrate a self-healing behaviour and humidity resistance effect on exposure to water vapour. Figure $5 \mathrm{~b}$ shows a comparison of the changes in colour of the perovskite layer with PEG (top) and the perovskite layer without PEG (bottom) after both were sprayed with water vapour for $60 \mathrm{~s}$. The perovskite film without PEG decomposed into $\mathrm{PbI}_{2}$ and turned yellow irreversibly. In contrast, the PEG scaffold perovskite film showed yellow in colour at first and recovered to black in $\sim 45 \mathrm{~s}$ after removing from the spray (Fig. 5b). This amazing self-healing behaviour is further vividly demonstrated in $120 \mathrm{~s}$ videos (Supplementary Movies 1 and 2). The self-healing capability of the PPSC device was also manifested in the $J-V$ characterization (Fig. 5c). The PCE degrades with smaller $V_{\mathrm{oc}}$ and $J_{\mathrm{sc}}$ after exposure to water vapour 

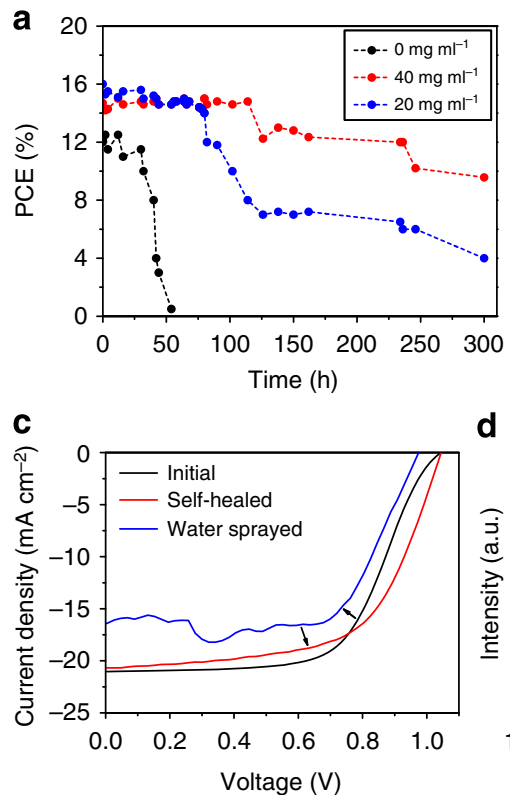

d b
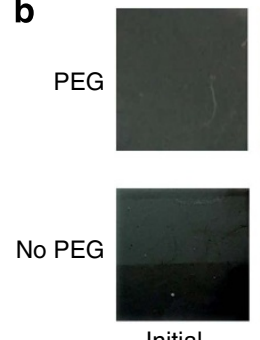

Initial
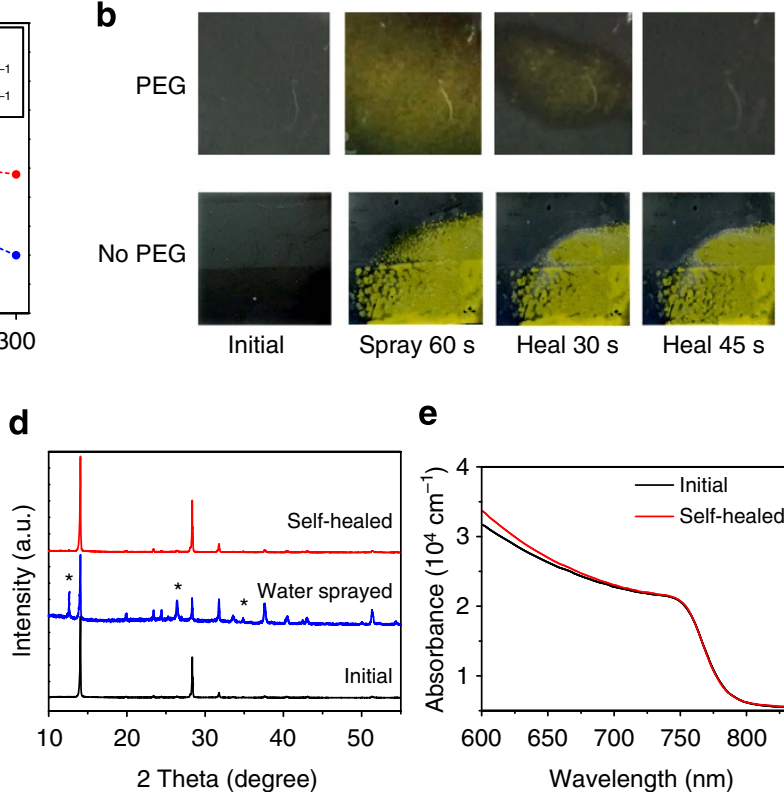

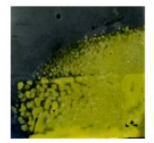

Spray $60 \mathrm{~s}$

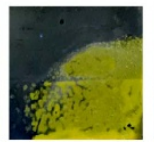

Heal $30 \mathrm{~s}$

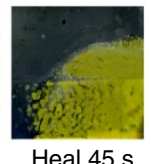

Heal $45 \mathrm{~s}$ e

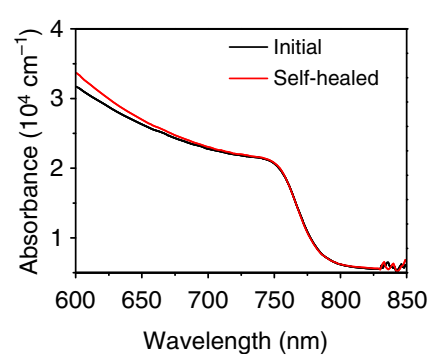

Figure 5 | Device stability and self-healing demonstration. (a) PCE evolution as a function of time of perovskite solar cells with 20 or $40 \mathrm{mg} \mathrm{ml}^{-1}$ PEG and without PEG scaffold exposed in high humid (70\% relative humidity) dark environment without any sealing. (b) Photographs of perovskite films with and without PEG showing colour change evolution after water-spraying for $60 \mathrm{~s}$ and kept in ambient air in $45 \mathrm{~s}$. (c) $J-V$ curves of PPSCs before and after water spray, revealing a complete recover of the cells in one minute when it puts back to ambient air. (d) X-ray diffraction evolution revealing the selfhealing process: X-ray diffraction pattern of initial perovskite film with PEG, after vapour sprayed and after 10 min from removing from water vapour, respectively. The symbol ‘*' represents for the peaks of $\mathrm{Pbl}_{2}$. (e) Absorption coefficient as function of wavelength for perovskite film before and after vapour spray and self-healing.

for $60 \mathrm{~s}$. Surprisingly, results showed that the $J-V$ curve can almost regain its original value in $45 \mathrm{~s}$, indicating that the PPSCs can heal itself when it is returned to ambient air after being sprayed with water. This unique humidity-resist characteristic is very suitable for practical applications because once the devices are exposed to very humid environment; they can self-heal to high PCE again in a short time when they return to sunlight again. Moreover, to further prove the self-healing property, perovskite film with PEG was sprayed with water vapour for $60 \mathrm{~s}$, then after self-healing, it was coated by Spiro-MeOTAD and Au electrode to fabricate into corresponding device, which showed photovoltaic performance comparable to its original PPSC devices without water spray (Supplementary Fig. 10).

The self-healing process was recorded by X-ray diffraction analysis (Fig. 5d). The peak at $12.7^{\circ}$ reveals that $\mathrm{PbI}_{2}$ phase formed when water vapour was sprayed on the film. After selfhealing, the $\mathrm{PbI}_{2}$ peak disappeared and the perovskite film fully recovered to its original crystal phase. The self-healing can also be demonstrated by the absorption spectra (Fig. 5e), which presented the same absorbance and similar Urbach energy ( $\sim 40 \mathrm{meV}$; ref. 29 ). The decomposition of perovskite phase is caused by the chemical reaction with water molecules ${ }^{30-32}$, which is manifested by the X-ray diffraction analysis of the perovskite film without PEG after water spray (Supplementary Fig. 11).

According to the observations in Fig. 2a-c, we conjecture that these entangled PEG molecules are anchored on the surface of perovskite grains by hydrogen bonding, and the formation is illustrated in Fig. 6a. The -OH I-interaction had been evidenced in the work by $\mathrm{Li}$ et $a l^{32}$. We use liquid state ${ }^{1} \mathrm{H}$ NMR measurements to prove such interactions. The proton NMR spectra of three samples were compared (Fig. 6b): deuterated DMSO solution with $\mathrm{MAPbI}_{3}$ (sample 1), with $\mathrm{MAPbI}_{3}+\mathrm{PEG}$ (sample 2) and with PEG (sample 3). In the signals of sample 3 , double methylene group linked to oxygen on both ends $\left(-\left[\mathrm{O}-\mathrm{CH}_{2}-\mathrm{CH}_{2}\right]_{n^{-}}\right)$is characterized by the peak at $\delta=3.48$ p.p.m. (Fig. 6b). An upfield chemical shift of $\Delta \delta$ $\sim-0.18$ p.p.m. with several splitting peaks is observed in sample 2. Such chemical shift can be explained by the hydrogen bond between $\mathrm{MA}^{+}$and $\mathrm{O}$ in PEG chain, which weakens the influence of $\mathrm{O}$ on protons of methylene in $-\left[\mathrm{O}-\mathrm{CH}_{2}-\mathrm{CH}_{2}\right]_{n}-$. Furthermore, the proton resonance signals of $-\mathrm{NH}_{3}^{+}$in sample 1 (peak at $\delta=7.33$ p.p.m.) shift towards upfield with $\Delta \delta \sim$ -0.13 p.p.m. in sample 2 (Fig. 6b), which can also be attributed to the hydrogen bonds discussed above. Such interaction is also evidenced by a dissolution experiment devised by us (Supplementary Fig. 12).

As presented in Fig. 6c, the improved stability and self-healing effect of the PPSC devices can be ascribed to the excellent hygroscopicity of the PEG molecules and their strong interaction with the perovskite. On one hand, the omnipresent PEG molecules can absorb water efficiently to form a compact moisture barrier around perovskite crystal grains with little water penetrating into the film. On the other hand, on water spray, the black perovskite film with PEG turned light yellow ( $\mathrm{PbI}_{2}$ forms) at first. However, due to the strong interaction between MAI and PEG, (NMR measurements and a dissolution experiment in Supplementary Fig. 12), the MAI molecules were anchored by the nearby PEG molecules rather than escape away (process 1, 2 in Fig. 6c). After being kept away from water vapour, $\mathrm{PbI}_{2}$ in the film reacted with nearby MAI to regenerate the perovskite $\mathrm{MAPbI}_{3}$ phase, very similar to the two-step synthesis ${ }^{2}$ (process 3 in Fig. $6 \mathrm{c}$ ). The instant decomposition-regeneration mechanism explains the fast self-healing process in the PEG scaffold perovskite film.

\section{Discussion}

The hygroscopic PEG scaffold can stabilize the perovskite film, rendering the devices resistant to moisture with strong self-healing property. Hygroscopic polymer-scaffold architecture paved a new effective way in perovskite solar cell, to solve the 

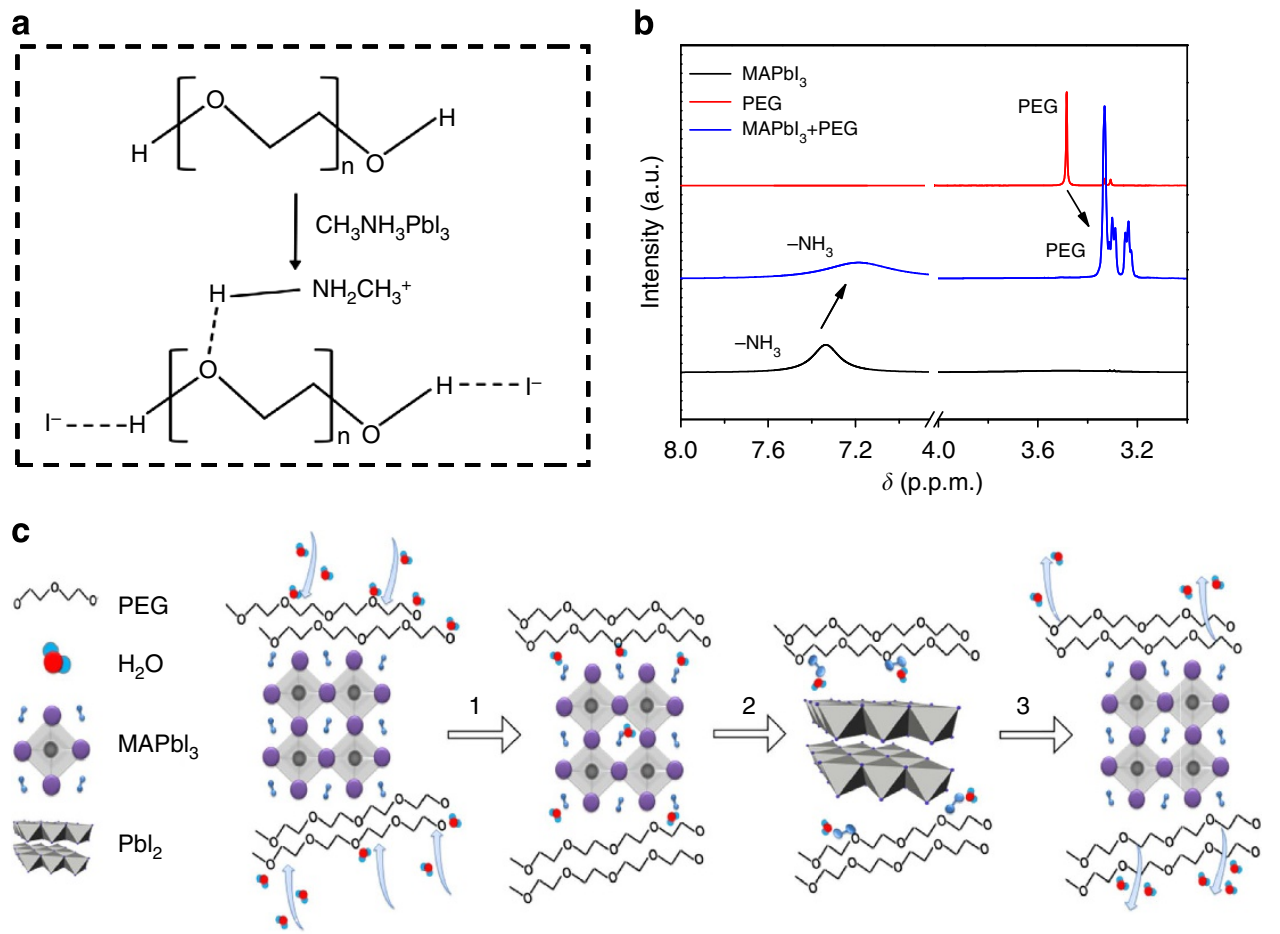

Figure 6 | Mechanism demonstration of self-healing. (a) Schematic diagram of the hydrogen bonding formation between PEG molecules and MAPbl ${ }_{3}$. (b) A comparison of NMR spectra from 3.0 to 8.0 p.p.m. among three samples: deuterated DMSO solutions with MAPbl ${ }_{3}$, mixture of MAPbl 3 + PEG and PEG, respectively. (c) Schematic diagram to show mechanisms for the self-healing properties in PPSCs: (1) Water absorb on perovskite; (2) Perovskite hydrolysis into $\mathrm{Pbl}_{2}$ and $\mathrm{MAl} \bullet \mathrm{H}_{2} \mathrm{O}$ by water; (3). Restrained MAI by PEG react with nearby $\mathrm{Pbl}_{2}$ to form perovskite again after water evaporates. PEG has a strong interaction with MAI, preventing it from evaporating, subsequently MAI and $\mathrm{Pbl}_{2}$ react in situ to form perovskite after the film was removed away from the vapour source.

hydrolysis problem in ambient air with greatly decreased package cost. The polymer-scaffold perovskite layer reinforces the architecture and improves strain tolerance. It may also facilitate production of flexible, wearable devices in the future. Future work will be focused on looking for cheap long-chain polymers which have stronger hygroscopicity and binding effect with MAI to protect the perovskite from decomposition in ambient environment. Moreover, by comparing the stability test result under light illumination (Supplementary Fig. 8) and in dark (Fig. 5a), we found that light has a strong destructive influence on stability performance. One would expect that this influence comes from decomposition of perovskite film accelerated by light with the aid of hydrolysis by water molecules under illumination (reactive equation in Supplementary Fig. 11). However, after $72 \mathrm{~h}$ light soaking, the perovskite film with PEG was not destructed compared with that without PEG from X-ray diffraction spectra (Supplementary Fig. 9). This indicated another important factor influencing the efficiency in addition to material decomposition. Hence, we speculate that $\mathrm{I}^{-}$ion migration ${ }^{33-36}$ may be induced or enhanced by light. Ion migration may answer for the poor stability under illumination, no matter in the traditional architecture without PEG scaffold or in our PPSCs, which needs further investigation. Further improvement needs be focused on revealing the mechanism of ion migration in the long-term stability issue, as well as how to inhibit it in PPSCs, which would lead to much better performance in stability test under illumination with high humidity.

\section{Methods}

Device fabrication and device characterization. All chemicals were purchased from Sigma-Aldrich or J\&K Scientific Ltd. unless otherwise stated. The photovoltaic devices were fabricated on FTO-coated glass (Pilkington, Nippon Sheet Glass). First, laser-patterned, FTO-coated glass substrates were cleaned by ultrasonic cleaned in deionized water, acetone and ethanol, followed by an ultraviolet treatment for $5 \mathrm{~min}$. Compact layers were deposited on the substrates by spin coating titanium diisopropoxide bis(acetylacetonate) solution (75\% in 2-propanol) diluted in ethanol (1:20, volume ratio) for two times and annealed at $450^{\circ} \mathrm{C}$ for $30 \mathrm{~min}$. After cooling to room temperature, the substrates were transferred to a hot plate at $90^{\circ} \mathrm{C}$ before spin coating. $\mathrm{CH}_{3} \mathrm{NH}_{3} \mathrm{I}$ was synthesized according to the reported procedure ${ }^{1}$. In a typical synthesis, $33.77 \mathrm{ml}$ methylamine (33\% in methanol) and $30 \mathrm{ml}$ of hydroiodic acid (57\% in water) were reacting in a $250 \mathrm{ml}$ flask at $0{ }^{\circ} \mathrm{C}$ for $2 \mathrm{~h}$ under stirring. The precipitate was formed by evaporation at $50^{\circ} \mathrm{C}$ for $1 \mathrm{~h}$. The product, methylammonium iodide $\mathrm{CH}_{3} \mathrm{NH}_{3} \mathrm{I}$, was washed with diethyl ether by stirring the solution for $30 \mathrm{~min}$, repeated three times, and then finally dried at $60^{\circ} \mathrm{C}$ in vacuum oven for $24 \mathrm{~h}$. The prepared $\mathrm{CH}_{3} \mathrm{NH}_{3} \mathrm{I}, \mathrm{PbCl}_{2}$ (Aldrich) (3:1) for 430 and $250 \mathrm{mg} \mathrm{ml}^{-1}$ solution was mixed with PEG (Sigma-Aldrich) and stirred in dimethylformamide at $60^{\circ} \mathrm{C}$ for $12 \mathrm{~h}$. The molar ratio of PEG monomers $\left(\mathrm{C}_{2} \mathrm{H}_{4} \mathrm{O}\right)$ to ultimate product $\mathrm{MAPbI}_{3}$ is $\sim 1: 1$ (PEG in $40 \mathrm{mg} \mathrm{ml}^{-1}$ ). The resulting solution was then coated onto the $\mathrm{TiO}_{2} / \mathrm{FTO}$ substrate by spin coating at 500 r.p.m. for $10 \mathrm{~s}$, and then 3,500/4,500/5,500 r.p.m. for $30 \mathrm{~s}$, for the solution with $20 / 40 / 80 \mathrm{mg} \mathrm{ml}^{-1}$ PEG, respectively. For different molecular weight $12,000 / 20,000 / 100,000 \mathrm{Da}$. with

$20 \mathrm{mg} \mathrm{ml}^{-1}$, we use the optimized $3.500 / 3.500 / 4.500$ r.p.m. to prepare the film. Then the substrate was dried on a hot plate at $60^{\circ} \mathrm{C}$ for $45 \mathrm{~min}$, then sintered at $105^{\circ} \mathrm{C}$ for $70 \mathrm{~min}$. For the preparation of peroskite film without PEG, the optimized sintering temperature is $100^{\circ} \mathrm{C}$. After cooling to room temperature, the hole transport material was spin coated onto the perovskite film at 3,000 r.p.m. for $40 \mathrm{~s}$. The spin coating

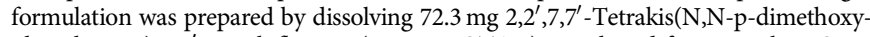
phenylamino)-9, $9^{\prime}$-spirobifluorene(spiro-MeOTAD), purchased from Yingkou OPV Tech New Energy Co. Ltd., $30 \mu \mathrm{l} 4$-tert-butylpyri-dine and $20 \mu \mathrm{l}$ of a stock solution of $520 \mathrm{mg} \mathrm{ml}^{-1}$ lithium bis (trifluoromethylsulphonyl) imide in acetonitrile in $1 \mathrm{ml}$ chlorobenzene. Finally, 90-nm-thick gold electrodes were deposited on top of the devices by evaporation at $\sim 10^{-4}$ mbar. The active area of the electrode was fixed at $9 \mathrm{~mm}^{2}$.

The surface morphology and EDS mapping of the perovskite thin film was characterized by SEM (Nano430, FEI). The instrument uses an electron beam accelerated at $15 \mathrm{kV}$, enabling operation at a variety of currents. Considering that only PEG polymer contains oxygen element among those materials used in perovskite thin film synthesis, here oxygen stands for PEG polymer, lead for perovskite. HAADFSTEM is examined by Cs-corrected FEI (Titan G2 80-200) transmission electron microscope operating at an accelerating voltage of $300 \mathrm{kV}$, equipped with ChemiSTEM EDS detector, which enables very quick high-resolution element mapping. The sample is prepared from perovskite precursor solution spin coated on TEM grid (3,000 r.p.m.), then annealed at $105^{\circ} \mathrm{C}$ for $70 \mathrm{~min}$. 
For NMR measurement, it is examined by Bruker 600 UltraShield using pulse signal. We use deuterated DMSO as solvent. The $\mathrm{CH}_{3} \mathrm{NH}_{3} \mathrm{PbI}_{3}$ solution is prepared from $\mathrm{CH}_{3} \mathrm{NH}_{3} \mathrm{I}, \mathrm{PbI}_{2}$ (Aldrich; 1:1) for 53 and $153 \mathrm{mg} \mathrm{ml}^{-1}$ solution and stirred in DMSO at $60^{\circ} \mathrm{C}$ for $12 \mathrm{~h} . \mathrm{CH}_{3} \mathrm{NH}_{3} \mathrm{PbI}_{3}$ solution mixed with PEG (Sigma-Aldrich) is prepared by adding $40 \mathrm{mg}$ PEG (molecule weight: $20,000 \mathrm{Da}$ ) to $1 \mathrm{ml}$ $\mathrm{CH}_{3} \mathrm{NH}_{3} \mathrm{PbI}_{3}$ solution.

For X-ray diffraction measurement, flat $\mathrm{PbI}_{2}$ and $\mathrm{TiO}_{2} / \mathrm{PbI}_{2}$ nanocomposites were deposited on glass slides using the above-mentioned procedures. X-ray powder diagrams were recorded on an X'PertMPD PRO from PANalytical equipped with a ceramic tube $(\mathrm{Cu}$ anode, $\lambda=1.5406 \AA)$, a secondary graphite (002) monochromator and a RTMS X'Celerator detector, and operated in BRAGGBRENTANO geometry. The samples were mounted without further modification, and the automatic divergence slit and beam mask were adjusted to the dimensions of the thin films. A step size of $0.008 \mathrm{deg}$ was chosen and an acquisition time of up to $7.5 \mathrm{~min}$ per deg. A baseline correction was applied to all X-ray powder diagrams to remove the broad diffraction peak arising from the amorphous glass slide.

Steady-state PL spectra were measured using a $\mathrm{He}-\mathrm{Cd}$ laser $(325 \mathrm{~nm}$ in wavelength) and green laser (514 $\mathrm{nm}$ in wavelength) guided by a micro-zone confocal Raman spectroscope (Renishaw inVia microRaman system) as the laser beam with a spot size diameter of $2 \mu \mathrm{m}$. The collected duration is $\sim 5 \mathrm{~ms}$. The time-resolved fluorescence spectra were recorded with a high-resolution streak camera system (Hamamatsu C10910). We used an amplified mode-lock Ti: Sapphire femtosecond laser system (Legend, Coherent) and a two-stage optical parametric amplifier (OperA Solo, Coherent) to generate the pump beam with a repetition rate of $1 \mathrm{KHz}$. All the samples were excited by $517 \mathrm{~nm}$ at room temperature with $110 \mathrm{~nJ} \mathrm{~cm}^{-2}$.

The electrochemical impedance spectrum and cyclic voltammograms were measured using a potentiostat/galvanostat (SP-150, Bio-Logic, France). The frequency can be tuned from $0.1 \mathrm{~Hz}$ to $1 \mathrm{MHz}$. All the samples were measured under $10 \mathrm{~mW} \mathrm{~cm}^{-2}$.

The $J-V$ characteristics were obtained using an Agilent B2900 Series precision source/measure unit, and the cell was illuminated by a solar simulator (Solar IV-150A, Zolix) under AM1.5 irradiation $\left(100 \mathrm{~mW} \mathrm{~cm}^{-2}\right)$. Light intensity was calibrated with a Newport calibrated KG5-filtered Si reference cell. We use black mask to define the cells' area, and the masking effect is confirmed by testing the $J_{\mathrm{sc}}$ with and without it, which has a $5 \% J_{\mathrm{sc}}$ difference. The $J-V$ curves are tested from 1.5 to $-0.2 \mathrm{~V}$ with a scan velocity $500 \mathrm{mV} \mathrm{s}^{-1}$. The masked active area is $9 \mathrm{~mm}^{2}$.

Stability test. Unsealed PPSCs and PSCs were put near a humidifier to control its relative humidity $\sim 70 \%$. For the stability test under dark, the cells were stored in a black box with $70 \%$ relative humidity, and were tested every $8 \mathrm{~h}$. For the stability tests under continuous light illumination, light source ranges from 300 to $800 \mathrm{~nm}$ wavelength with $70 \mathrm{~mW} \mathrm{~cm}^{-2}$ was used. $J-V$ curves were recorded under AM1.5 light irradiation. The temperature is controlled $\sim 30^{\circ} \mathrm{C}$. Three devices were measured in this way and demonstrate excellent repeatability. For the self-healing behaviour, we sprayed the water vapour for $60 \mathrm{~s}$ onto the resulting devices by humidifier. $J-V$ curves were collected before and right after water vapour exposure under standard illumination AM1.5.

\section{References}

1. Kim, H. S. et al. Lead iodide perovskite sensitized all-solid-state submicron thin film mesoscopic solar cell with efficiency exceeding 9\%. Sci. Rep. 2, 591 (2012).

2. Burschka, J. et al. Sequential deposition as a route to high-performance perovskite-sensitized solar cells. Nature 499, 316-319 (2013).

3. Lee, M. M. et al. Efficient hybrid solar cells based on meso-superstructured organometal halide perovskites. Science 338, 643-647 (2012).

4. Liu, M., Johnston, M. B. \& Snaith, H. J. Efficient planar heterojunction perovskite solar cells by vapour deposition. Nature 501, 395-398 (2013).

5. Zhou, H. et al. Interface engineering of highly efficient perovskite solar cells. Science 345, 542-546 (2014).

6. Mei, A. et al. A hole-conductor-free, fully printable mesoscopic perovskite solar cell with high stability. Science 345, 295-298 (2014).

7. Liu, D. \& Kelly, T. L. Perovskite solar cells with a planar heterojunction structure prepared using room-temperature solution processing techniques. Nat. Photon. 8, 133-138 (2014).

8. Jeon, N. J. et al. Solvent engineering for high-performance inorganic-organic hybrid perovskite solar cells. Nat. Mater. 13, 897-903 (2014).

9. Chiang, C.H, Tseng, Z. L. \& Wu, C. G. Planar heterojunction perovskite/ $\mathrm{PC}_{71} \mathrm{BM}$ solar cells with enhanced open-circuit voltage via a (2/1)-step spincoating process. J. Mater. Chem. A 2, 15897-15903 (2014).

10. Jeon, N. J. et al. Compositional engineering of perovskite materials for highperformance solar cells. Nature 517, 476-480 (2015)

11. Wei, J. et al. Hysteresis analysis based on the ferroelectric effect in hybrid perovskite solar cells. J. Phys. Chem. Lett. 5, 3937-3945 (2014).

12. Kojima, A., Teshima, K., Shirai, Y. \& Miyasaka, T. Organometal halide perovskites as visible-light sensitizers for photovoltaic cells. J. Am. Chem. Soc. 131, 6050-6051 (2009).

13. Xiao, Z. et al. Giant switchable photovoltaic effect in organometal trihalide perovskite devices. Nat. Mater. 14, 193-198 (2015).
14. Stranks, S. D. et al. Electronhole diusion lengths exceeding 1 micrometer in an organometal trihalide perovskite absorber. Science 342, 341-344 (2013).

15. Lin, Q. et al. Electro-optics of perovskite solar cells. Nat. Photon.s 9, 106-112 (2015).

16. Nie, W. Y. et al. High-efficiency solution-processed perovskite solar cells with millimeter-scale grains. Science 347, 522-525 (2015).

17. Dong, Q. F. et al. Electron-hole diffusion lengths $>175 \mu \mathrm{m}$ in solution-grown $\mathrm{CH}_{3} \mathrm{NH}_{3} \mathrm{PbI}_{3}$ single crystals. Science 347, 967-970 (2015).

18. Eperon, G. E. et al. Morphological control for high performance, solutionprocessed planar heterojunction perovskite solar cells. Adv. Funct. Mater. 24, 151-157 (2014).

19. Thompson, C. V. Solid-state dewetting of thin films. Annu. Rev. Mater. Res. 42, 399-434 (2012).

20. Giles, E. Eperon et al. The importance of moisture in hybrid lead halide perovskite thin film fabrication. ACS Nano 10, 1021 (2015).

21. Jeon, Y. J. et al. Planar heterojunction perovskite solar cells with superior reproducibility. Sci. Rep. 4, 6953 (2014).

22. Xie, F. et al. Vacuum-assisted thermal annealing of $\mathrm{CH}_{3} \mathrm{NH}_{3} \mathrm{PbI}_{3}$ for highly stable and efficient perovskite solar cells. ACS Nano 9, 639-646 (2015).

23. Ahn, N. et al. Highly reproducible perovskite solar cells with average efficiency of $18.3 \%$ and best efficiency of $19.7 \%$ fabricated via lewis base adduct of lead(II) iodide. J. Am. Chem. Soc. 137, 8696-8699 (2015).

24. Kaltenbrunner, M. et al. Flexible high power-per-weight perovskite solar cells with chromium oxide-metal contacts for improved stability in air. Nat. Mater. 14, 1032-1039 (2015).

25. Song, T. B. et al. Unraveling film transformations and device performance of planar perovskite solar cells. Nano Energy 12, 494-500 (2015).

26. Yu, H. et al. The role of chlorine in the formation process of " $\mathrm{CH}_{3} \mathrm{NH}_{3} \mathrm{PbI}_{3}$ ${ }_{\mathrm{x}} \mathrm{Cl}\left({ }_{\mathrm{x}}\right)$ " perovskite. Adv. Funct. Mater. 24, 7102-7108 (2014).

27. Quilettes, D. W. et al. Impact of microstructure on local carrier lifetime in perovskite solar cells. Science 348, 683-686 (2015).

28. Shao, Y. C. et al. Origin and elimination of photocurrent hysteresis by fullerene passivation in $\mathrm{CH}_{3} \mathrm{NH}_{3} \mathrm{PbI}_{3}$ planar heterojunction solar cells. Nat. Commun. 5, 5784 (2014).

29. Snaith, H. J. et al. Metal-halide perovskites for photovoltaic and light-emitting devices. Nat. Nanotechnol. 10, 391-402 (2015).

30. Baikie, T. et al. Synthesis and crystal chemistry of the hybrid perovskite $\left(\mathrm{CH}_{3} \mathrm{NH}_{3}\right) \mathrm{PbI}_{3}$ for solid-state sensitised solar cell applications. J. Mater. Chem. A 1, 5628-5641 (2013).

31. Dualeh, A. et al. Thermal behavior of methylammonium lead-trihalide perovskite photovoltaic light harvesters. Chem. Mater. 26, 6160-6164 (2014).

32. Li, X. et al. Improved performance and stability of perovskite solar cells by crystal crosslinking with $\omega$-ammonium-alkylphosphonic acid chlorides. Nat. Chem. 7, 703-711 (2015).

33. Zhang, Y. et al. Charge selective contacts, mobile ions and anomalous hysteresis in organic-inorganic perovskite solar cells. Mater. Horiz 2, 315 (2015).

34. Eames, C. et al. Ionic transport in hybrid lead iodide perovskite solar cells. Nat. Commun. 6, 7497 (2015).

35. Yang, T.-Y et al. The Significance of ion conduction in a hybrid organicinorganic lead-iodide-based perovskite photosensitizer. Angew. Chem. Int. Ed. 54, 7905-7910 (2015).

36. Azpiroz, J. M. et al. Defect migration in methylammonium lead iodide and its role in perovskite solar cell operation. Energy Environ. Sci. 8, 2118 (2015).

\section{Acknowledgements}

We thank Jinlong Pan, Professor Dongsheng Xu, Dr Zhenxuan Zhao, Professor Jianjun Tian, Professor Guozhong Cao and Professor Han Zhang for experimental help. We thank Yu Li and Professor Shufeng Wang for time-resolved PL measurements. We thank Professors Jixue Li and Ze Zhang for STEM observations. We also thank Professors Jun $\mathrm{Xu}$, Liping You and Li Chen for electron microscope help. This work was supported by National 973 projects (2013CB932602, 2011CB707601, MOST) from Ministry of Science and Technology, China, National Natural Science Foundation of China (NSFC51272007, 61571015, 11234001, 91433102, 11327902). Q.Z. acknowledges Beijing Nova Program (XX2013003) and the Program for New Century Excellent Talents in University of China.

\section{Author contributions}

Y.Z.., Q.Z. and D.Y. conceived the idea and designed the experiment. Y.Z., Y.Y., J.W. and W.Z. performed the experiment and analysed the data. Y.Z., Y.Y. and J.W. optimized the PCE to 15\%. H.L., Y.Z. and Q.Z. contributed to the experiment discussion, schematic diagram and image processing. D.Y. and Q.Z. supervised the project during the whole process. D.Y., Q.Z., H.L. and Y.Z.. co-wrote the manuscript. All authors read and comment on the manuscript.

\section{Additional information}

Supplementary Information accompanies this paper at http://www.nature.com/ naturecommunications 
Competing financial interests: The authors declare no competing financial interests.

Reprints and permission information is available online at http://npg.nature.com/ reprintsandpermissions/

How to cite this article: Zhao, Y. et al. A polymer scaffold for self-healing perovskite solar cells. Nat. Commun. 7:10228 doi: 10.1038/ncomms10228 (2016). (c) (i) This work is licensed under a Creative Commons Attribution 4.0 International License. The images or other third party material in this article are included in the article's Creative Commons license, unless indicated otherwise in the credit line; if the material is not included under the Creative Commons license, users will need to obtain permission from the license holder to reproduce the material. To view a copy of this license, visit http://creativecommons.org/licenses/by/4.0/ 